\title{
FAILED BACK SURGERY SYNDROME
}

\author{
By
Mohamed Ramadan El-Sawy, Ali Khodair and Islam Mohamed Al- Aghory \\ Department of Neurosurgery, Faculty of Medicine, Al-Azhar University, Egypt \\ E-mail: elsawymohamed666@gmail.com
}

\begin{abstract}
Background: Chronic low back pain is a serious health problem. Chronic pain affects negatively quality of life and should be treated as interest as personal handicapping issues.

Objective: To discuss etiologies and risk factors of failed back surgery syndrome (FBSS) with evaluation of different management modalities to help lowering its incidence and upgrading patient's outcome.

Patients and methods: This was a cross sectional retrospective study on randomized group of patients (50 patients) performed between May 2014 and May 2018 at El Sheikh Zayed specialized hospital. They complained from lower back pain with or without legs pain and had done one or more lumbar surgeries. All patients were subjected to history taking and neurological examination (motor power, stretch signs - strait leg raising, femoral stretch- and bladder control). Radiographic documentation was for all patients including magnetic resonance imaging (MRI) lumbar spinal stenosis (LSS).

Results: Forty-four patients $(88 \%)$ were managed by surgical re-intervention after clinical evaluation including complain analysis and neurological assessment and correlating it with pre-operative radiological findings. Six patients (12\%) were found to have no radiological findings correlated to their complaints.

Conclusion: Failed back surgery syndrome acts like a malignant disease that we are unable to completely treat it, but we can control it. In our study, we can catch many factors which will help. Patient selection to be fit candidate for lumbar surgery is a main matter.
\end{abstract}

Keywords: Failed Back Surgery Syndrome, Post-Laminectomy Syndrome.

\section{INTRODUCTION}

Back pain is a highly prevalent condition that can have a tremendous social, financial, and psychological impact on a patient's life. Low back pain is a worldwide problem, with an estimated 9.4\% global incidence, creating more disability than any other condition in the world. Low back pain (LBP) has been estimated to have a lifetime prevalence of $60 \%-80 \%$ among the global population, making it one of the most common health complaints (Damian et al., 2010).
As a consequence of the large number of patients with LBP who have sought treatment, a substantial increase in those undergoing surgery has been observed over the past two decades (James and Orso, 2018). Between 1998 and 2008, the yearly number of lumbar fusion surgeries performed in the United States increased from 77,682 to 210,407 , with the total number of spinal operations exceeding one million in 2002. During the same period, the rate of laminectomies increased by $11.3 \%$ from 92,390 to 107,790 (Rajaee et al., 2012). 
The aim of the present work was to discuss etiologies and risk factors of FBSS with evaluation of different management modalities to help lowering its incidence and upgrading patient's outcome.

\section{PATIENTS AND METHODS}

In retrospective study, results of fifty patients after one, two or three lumbar surgeries were analyzed. Revision surgery was performed between May 2014 and May 2018 at El Sheikh Zayed specialized hospital. The following data were evaluated: Pre and postoperative clinical examination, results of preoperative diagnostic evaluation (Magnetic Resonance Imaging [MRI] scans), preoperative diagnosis leading to revision, intraoperative findings, operative procedures and outcome status. The analyses of leading factors for reintervention after primary lumbar surgery were based on the preoperative diagnosis and the intraoperative findings. The preoperative diagnosis was based one physical and neurologic examination and results of MRI scans. All patients submitted to personal history including age, occupation and smoking as a special habit. Also, detailed history about number lumbar interventions they did. Data focused on symptomatic complain before primary lumbar procedure done LBP with or without radicular pain or motor dysfunction. Outcome after surgery if total relief, residual complain, no relief, and if new complain developed. For patients who done one or more reinterventions, history analysis focused on new complain similarity to complain before primary procedure, interval between each procedure and outcome after each intervention. Also, history about invasive pain therapy trials for most of patients submitted to our study and outcome of these trials.

\section{Statistical analysis:}

Data were analyzed using Statistical Program for Social Science (SPSS) version 24. Quantitative data were expressed as mean \pm standard deviation (SD). Qualitative data were expressed as frequency and percentage.

\section{RESULTS}

We studied randomly selected 50 patients, 31 male and 19 females and age ranged between 24 to 75 years old. Twenty seven of 31 male patients had jobs and 4 pensioners. Nine females working and 10 were house wives. Twelve patients (10 males and 2 females) had advantage of non-governmental insurance for health. Half patients were smokers (21 males and 4 females), 21 were smoking cigarettes as at least one box per day for 5-20 years and 4 patient regularly daily smoking Hookah (Shisha) for 5-15 years.
Table (1): Showed the description of demographic data in all studied patients. As regard age, the mean age of all studied patients was $46.04 \pm 11.4$ years with minimum age of 24 years and maximum age of 75 years. As regard sex, there were 31 males $(62 \%)$ and 19 females $(38 \%)$ in all studied patients. As regard smoking, there were 25 non-smokers $(50 \%)$ and 25 smokers $(50 \%)$ in all studied patients. As regard NGIS, there were 38 non-served patients $(76 \%)$ and 12 served patients $(24 \%)$ in all studied patients. 
Table (1): Description of demographic data in all studied patients

\begin{tabular}{|c|c|c|c|}
\hline \multicolumn{2}{|c|}{} & \multicolumn{2}{c|}{$\begin{array}{c}\text { Studied patients } \\
(\mathbf{N}=\mathbf{5 0})\end{array}$} \\
\hline \multirow{2}{*}{ Age (years) } & Mean \pm SD & \multicolumn{2}{|c|}{$46.04 \pm 11.4$} \\
\cline { 2 - 4 } Sex & Min- Max & \multicolumn{2}{|c|}{$24-75$} \\
\hline \multirow{2}{*}{ Smoking } & Male & 31 & $62 \%$ \\
\cline { 2 - 4 } & Female & 19 & $38 \%$ \\
\hline $\begin{array}{c}\text { NGIS } \\
\text { Nervices) }\end{array}$ & Non-smoker & 25 & $50 \%$ \\
\cline { 2 - 4 }$\left(\begin{array}{c}\text { Non-governmental insurance } \\
\text { servicer }\end{array}\right.$ & Non-served & 25 & $50 \%$ \\
\cline { 2 - 4 } & Served & 12 & $24 \%$ \\
\hline
\end{tabular}

As regard to main complaints prior to 1ry intervention, $20(40 \%)$ presented complaining only from true sciatic pain, 4 $(8 \%)$ presented with neurogenic claudication only, 9 (18\%) presented with
LBP and sciatic pain, $17(34 \%)$ presented with LBP and neurogenic claudication and no one presented with LBP only neither motor deficit (Tables 2).

Table (2): Main complaints prior to 1ry intervention

\begin{tabular}{|c|c|}
\hline Complaints & Number of cases \\
\hline True sciatic pain only & 20 \\
\hline Neurogenic claudication only & 4 \\
\hline LBP and sciatic pain & 9 \\
\hline LBP and neurogenic claudication & 17 \\
\hline LBP only neither motor deficit & No cases \\
\hline
\end{tabular}

When we compared between complaint before 1ry intervention and complaint prior to 2 nd intervention, we noted 13 patient $(26 \%)$ whose main complaint was leg pain without LBP and 1ry intervention proceeded as decompression without fixation, had developed newer LBP as complaint before 2nd surgery. 20 patients (40\%) presented initially with LBP and Legs pain still complaining LBP regardless of 1ry operative procedure. 15 cases $(30 \%)$ presented before 2 nd surgery complaining recurrent leg pain (sciatica and/or claudication). 5 (10\%) patients were presented with motor deficit (two of them were in cauda equina symptoms).
As regard to Leg pain, 33 patients $(66 \%)$ were submitted to 2nd surgery with same complain before 1st surgery. Furthermore, 8 patients $(16 \%)$ submitted with new complain as sciatic pain became claudication pain or suffer another side of initial complain with 5 patients (10\%) presented with motor deficit. 5 patients (10\%) presented to 2nd surgery with persistent LBP only. 10 patients submitted for 3rd surgery with same complaint as before 1st and 2nd surgery (one of them was in cauda equina syndrome). Also, the same for 4 presented for 4th surgery (one of them was in cauda) (Table 3). 
Table (3): Leg complaints prior to each surgical intervention

\begin{tabular}{|c|c|c|c|}
\hline Groups & $\begin{array}{c}\text { Cases complaint } \\
\text { before } 2^{\text {nd }} \\
\text { surgery }\end{array}$ & $\begin{array}{c}\text { Cases complaint } \\
\text { before } 3^{\text {rd }} \\
\text { surgery }\end{array}$ & $\begin{array}{c}\text { Cases complaint } \\
\text { before } 4^{\text {th }} \\
\text { surgery }\end{array}$ \\
\hline $\begin{array}{c}\text { Presentations } \\
\text { complain }\end{array}$ & 33 & $10^{*}$ & $4^{*}$ \\
\hline $\begin{array}{c}\text { Presented with new } \\
\text { complain as sciatic } \\
\text { pain became } \\
\text { claudication pain or } \\
\text { suffer another side of } \\
\text { initial complain }\end{array}$ & 8 & - & - \\
\hline $\begin{array}{c}\text { Presented with motor } \\
\text { deficit }\end{array}$ & 5 & - & - \\
\hline $\begin{array}{c}\text { Presented with } \\
\text { persistent LBP only }\end{array}$ & 5 & - & - \\
\hline \multicolumn{2}{|c|}{} \\
\hline
\end{tabular}

* Number of all cases submitted for 3rd and 4th revision in our study

Table (4): Showed the description of old procedure technique in all studied patients. Double laminectomy was done in 5 patients $(10 \%)$, Fenestration unilateral one lamina was done in 6 patients $(12 \%)$, Fixation one segment was done in 2 patients (4\%), Fixation one segment with single laminectomy was done in 4 patients (8\%), Fixation two segment with double laminectomy was done in 7 patients
(14\%), Fixation three segments with three laminectomies was done in 2 patients (4\%), Inter-laminar discectomy was done in 2 patients (4\%), Inter-laminar one segment was done in 2 patients (4\%), Single hemi-laminectomy was done in 7 patients (14\%), Single laminectomy was done in 9 patients $(18 \%)$ \& Single laminectomy with discectomy was done in 4 patients $(8 \%)$.

Table (4): Description of old procedure technique in all studied patients

\begin{tabular}{|c|c|c|}
\hline Old & \multicolumn{2}{c|}{$\begin{array}{c}\text { Studied patients } \\
\text { procedure technique }\end{array}$} \\
Double laminectomy & 5 & $10 \%$ \\
\hline Fenestration unilateral one lamina & 6 & $12 \%$ \\
\hline Fixation one segment & 2 & $4 \%$ \\
\hline Fixation one segment with single laminectomy & 4 & $8 \%$ \\
\hline Fixation two segment with double laminectomy & 7 & $14 \%$ \\
\hline Fixation three segments with three laminectomies & 2 & $4 \%$ \\
\hline Inter-laminar discectomy & 2 & $4 \%$ \\
\hline Inter-laminar one segment & 2 & $4 \%$ \\
\hline Single hemi-laminectomy & 7 & $14 \%$ \\
\hline Single laminectomy & 9 & $18 \%$ \\
\hline Single laminectomy with discectomy & 4 & $8 \%$ \\
\hline
\end{tabular}

Figure (1): showed the description of our management in all studied patients. Added laminectomy was done in 27 patients (54\%), discectomy was done in
11 patients $(22 \%)$, residual lateral recess decompression was done in 19 patients (38\%), Adhesolysis was done in 23 patients $(46 \%)$, bilateral TP screws 
fixation was done in 39 patients $(78 \%)$, referred for pain therapy was done in 6 patients $(12 \%) \&$ dural repair was done in 2 patients $(4 \%)$.

\section{Our management}

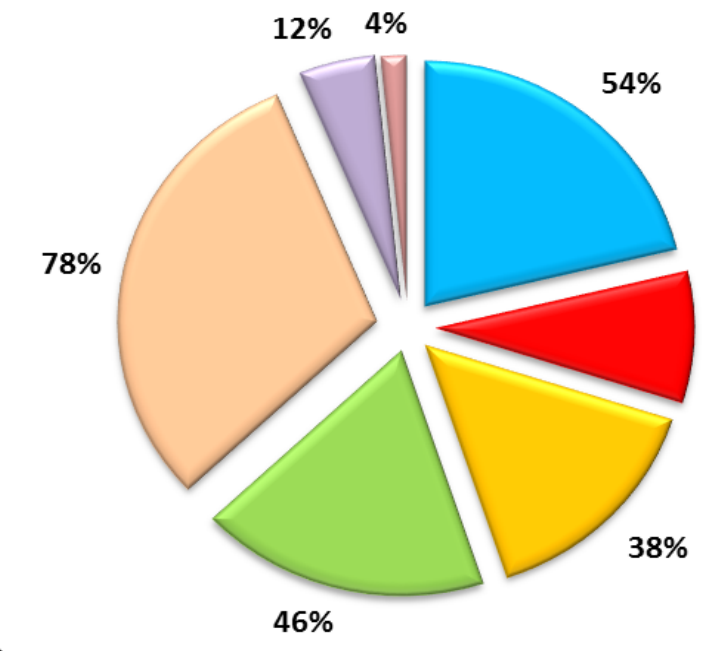

$\square$ Added laminectomy
$\square$ Discectomy
$\square$ Residual Lateral recess decompression
$22 \% \quad \square$ Adhesolysis
$\square$ Bilateral TP screws fixation
$\square$ Referred for pain therapy
$\square$ Dural repair

Figure (1): Description of our management in all studied patients

Figure (2): showed the description of failure causes in all studied patients. Failure was due to recurrent disc in 10 patients $(20 \%)$, instability in 15 patients $(30 \%)$, inadequate decompression in 17 patients (34\%), epidural fibrosis in 24 patients $(48 \%)$, Instability 2ry to aggressive decompression in 2 patients (4\%), Pseudo-meningocele in 2 patients (4\%), infection in 1 patient $(2 \%)$, broken screws in 2 patients $(4 \%) \&$ adjacent segment disease in 9 patients (18\%).

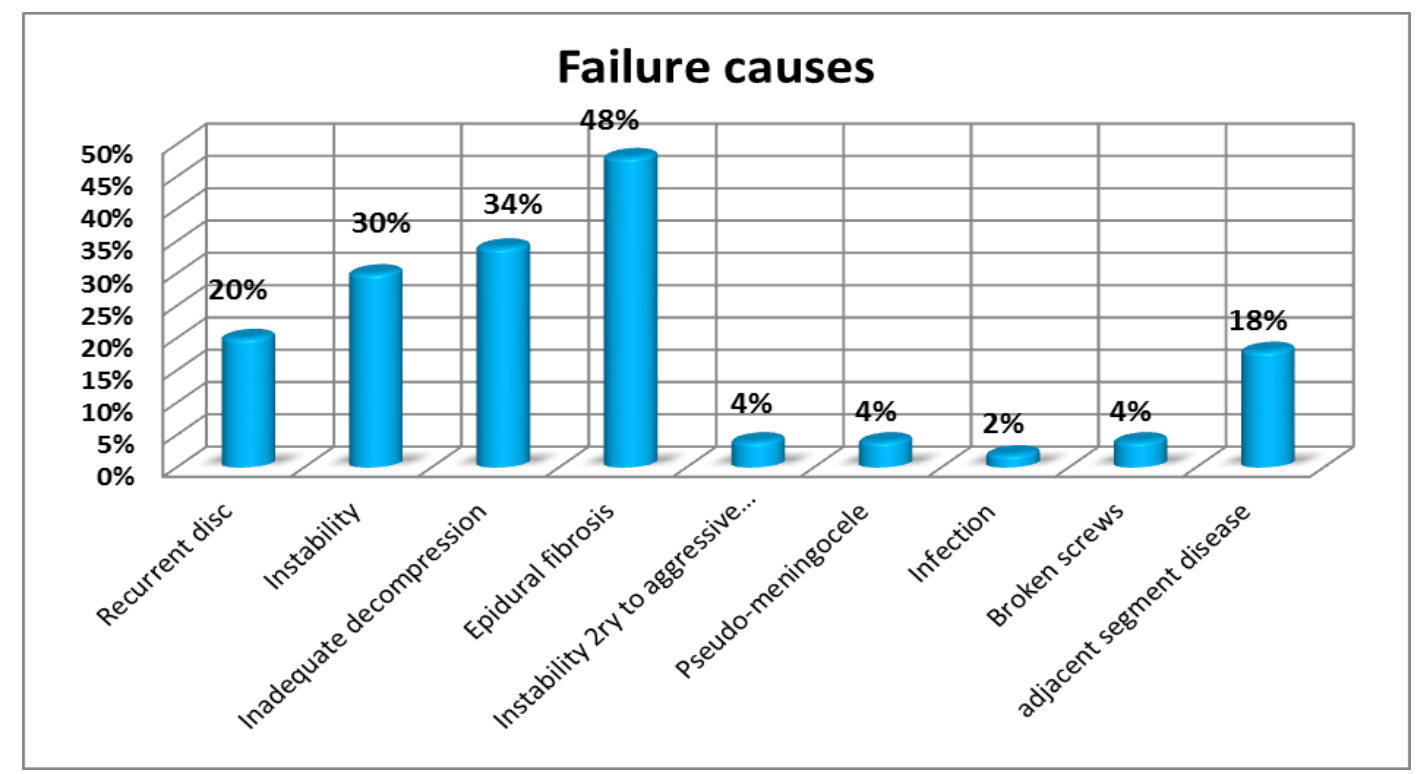

Figure (2): Description of failure causes in all studied patients 


\section{DISCUSSION}

Change in age and sex group between our study, Assaker and Zairi (2015) and Rothenfluh et al. (2015) was not significant with relatively predominance for male than females and for middle and older age groups.

In our study, we have $24 \%$ of patients served by non-governmental insurance care for health. Our society suffers low economic status and we unfortunately don't have statistical studies to analyze workers psychological status and their job satisfaction. But many patients served by non-governmental insurance claimed non satisfactory post-surgical results.

Chan and Peng (2011), described that Poor surgical success in the presence of worker's compensation claim has been consistent finding throughout the spinal surgery literature.

$50 \%$ of patients submitted to our study were smokers for at least 5 years. Smoking was behavioral risk factor not to be neglected with evidenced hazards of smoking which increases risk of delayed wound healing and infection.

Sandén et al. (2011) stated that smokers had more a more regular use of analgesics, worsened walking ability and inferior overall quality of life 2 years after surgery compared with nonsmokers.

In our study, we found that $32 \%$ of patients complained unsatisfying results after 1ry surgery and radiological and revision operative findings revealed that they inadequately decompressed as neglected lateral recess stenosis, inappropriate foraminotomy or limited laminectomy. Kuniya et al. (2014), stated that inadequate decompression in the lateral recess and particularly in the neural foramens is the most common cause of poor surgical technique leading to FBSS, representing $25 \%-29 \%$ of the cases.

In our study, we found (4\%) developed recurrent segmental pathology as new instability and their radiological findings described over aggressive decompression involving partial facetectomy without fixation. This could be a leading factor to instability. Nguyen et al. (2011), described in that study that Judicious decompression may also lead to instability if $>33 \%$ of the articular surface is bilaterally removed or if $100 \%$ is unilaterally removed. McKillop et al. (2014) described that over aggressive decompression may lead to spinal instability and pain.

In our study, we have $20 \%$ of patients whose 1ry surgery were non aggressive decompression only as laminectomy with or without discectomy without spinal fixation. Their radiological finding revealed instability at site of 1ry surgery or adjacent segments. Lumbar decompressed surgery may affect spine dynamics and progression of spondilodegenerative changes of operated and adjacent segments. Chan and Peng (2011) showed each form of spinal operation has the potential to alter the distribution of weight among the structures of the spine. Also, Sandén et al. (2011) concluded the facet joints may become incompetent following laminectomy resulting in axial pain.

Parker et al. (2015) described that discectomy may also create changes in the biomechanics of the spine, resulting in increased load distribution on adjacent segments accelerating preexisting disc degeneration. In our study 10 patients 
(20\%) submitted to revision with clinical and radiological finding described true recurrent disc in spite of successful 1ry surgery as discectomy without spinal fixation. Eun et al. (2012) described similar results to our study as recurrent disc herniations following discectomy are known to occur in up to $15 \%$ of patients either at the site of operation or in adjacent segment. Amer et al. (2018) described results with relatively wide range $(6-23 \%)$ for recurrent disc herniation at either same site or adjacent segment.

In our study, $46 \%$, in their operative notes described epidural adhesions to old bed where lamina exposed entrapping theca and roots. Chan and Peng (2011) described that epidural fibrosis is probably inevitable after any surgery that involves manipulation of epidural space. This fibrosis may be the causative or contributing factor to persistent pain in (20-36\%) of FBSS patients.

We have $16 \%$ submitted to revision as they developed new pathology described radiologically after 1ry spinal fixation by transpedicular system as adjacent segment over stress. Stressed Adjacent segment may be expressed by canal stenosis or spondylolisthesis. Harrop et al. (2010) mentioned results higher than ours as incidence of clinical adjacent segment disease is approximately $27 \%$. Their results percentage was higher than ours, but their study was only for patients who underwent spinal arthrodesis. Epstein (2015) found that the incidence of ASD, following open or MI lumbar instrumented fusions, ranged up to 30 .

$4 \%$ in our study submitted for revision to correct surgical dural injury and
Pseudomeningocele formation, also $4 \%$ submitted for debridement of wound infection. Chan and Peng (2011) described that early identification and management of that complication is important as they can rapidly progress to permanent neurological deficits and death. Assaker and Zairi (2015) described that complications of surgery such Pseudomeningocele and infection can contribute to persistent pain in the postoperative period.

In our study, $12 \%$ whose their 1ry procedure including fixation by single or more segments including sacrum, their radiological findings were not correlated with their neurological complain and their clinical examination was augmenting sacroiliac joint (SIJ) source of pain. They were not submitted to surgery and managed by pain therapist for SIJ disease and their symptoms improved. Also, Yoshihara (2012) described that the SIJ is a possible source of persistent pain or new pain with failed back surgery syndrome after lumbar/lumbosacral fusion. Baber and Erdek (2016) augment our opinion that fusion of lumbar spine to sacrum as well as fusion of multiple segments may lead to SIJ disease. Lee et al. (2019) described that the average time to new onset symptoms was 22 months.

In our study, $4 \%$ submitted to surgery to remove broken screws and re apply new screws with no history of crushable accidents. We did not find studies mentioned similar cases but, we suggest that it may be cons of spinal fixation.

\section{CONCLUSION}

Selected patients should be well investigated with MRI with full dynamic $\mathrm{x}$ ray to and if possible, CT imaging to help 
accurate surgical model. Post-operative rehabilitation is as important as in cooperation with physical therapy specialists to help patient come back gradually to his normal life.

\section{REFERENCES}

1. Amer S, Marie-José L, Maroun R, Gaby $\mathrm{K}$ and Khalil K. (2018): Etiology, Evaluation, and Treatment of Failed Back Surgery Syndrome. Asian Spine J., 12(3):574-585.

2. Assaker R and Zairi F. (2015): Failed back surgery syndrome: to re-operate or not to reoperate? A retrospective review of patient selection and failures. Neurochirurgie., 61(1): 77-82.

3. Baber $Z$ and Erdek MA. (2016): Failed back surgery syndrome: current perspectives. J Pain Res., 9:979-87.

4. Chan $C$ and Peng P. (2011): Failed back surgery syndrome. Pain Med., 12:577-606.

5. Damian H, Lyn M, Peter B, Fiona B, Anthony W and Christopher B. (2010): The global burden of low back pain: estimates from the Global Burden of Disease. Ann Rheum Dis., 73:968-74.

6. Epstein NE. (2015): Adjacent level disease following lumbar spine surgery: A review. Surg Neurol Int., 6(24): 591-599.

7. Eun SS, Lee HY, Lee SH, Kim KH and Liu WC. (2012): MRI versus CT for the diagnosis of lumbar spinal stenosis. J Neuroradiol., 39(2):104-109.

8. Harrop JS, Jim AY, Mitch M, Peggy V, Pascal J and Christopher M. (2010): Lumbar adjacent segment degeneration and disease after arthrodesis and total disc arthroplasty. Spine, 33(15):1701-7.

9. James RD and Orso LO. (2018): Failed Back Surgery Syndrome: A Review Article. Asian Spine J., 12(2):372-379.
10. Kuniya H, Aota Y, Kawai T, Kaneko K, Konno T and Saito T. (2014): Prospective study of superior cluneal nerve disorder as a potential cause of low back pain and leg symptoms. J Orthop Surg Res., 9(1):1-6.

11. Lee YC, Lee R, Harman C. (2019): The incidence of new onset sacroiliac joint pain following lumbar fusion. Journal of Spine Surgery, 5(3): 122-130.

12. McKillop AB, Carroll LJ and Battié MC. (2014): Depression as a prognostic factor of lumbar spinal stenosis: a systematic review. Spine J., 14(5):837-846.

13. Nguyen TH, Randolph DC, Talmage J, Succop P and Travis R. (2011): Long-term outcomes of lumbar fusion among workers' compensation subjects: a historical cohort study. Spine, 36(4):320-331.

14. Parker SL, Mendenhall SK and Godil SS. (2015): Incidence of low back pain after lumbar discectomy for herniาated disc and its effect on patient-reported outcomes. Clin Orthop Relat Res., 473:1988-99.

15. Rajaee SS, Bae HW, Kanim LE and Delamarter RB. (2012): Spinal fusion in the United States: analysis of trends from 1998 to 2008. Spine, 37:67- 76.

16. Rothenfluh DA, Mueller DA, Rothenfluh E and Min K. (2015): Pelvic incidence-lumbar lordosis mismatch predisposes to adjacent segment disease after lumbar spinal fusion. Eur Spine J., 24:1251-8.

17. Sandén B, Försth $P$ and Michaëlsson $K$. (2011): Smokers show less improvement than nonsmokers two years after surgery for lumbar spinal stenosis: a study of 4555 patients from the Swedish spine register. Spine, 36(13):1059-1064.

18. Yoshihara H. (2012): Sacroiliac joint pain after lumbar/lumbosacral fusion: current knowledge. Eur Spine J., 21(9): 1788-1796. 


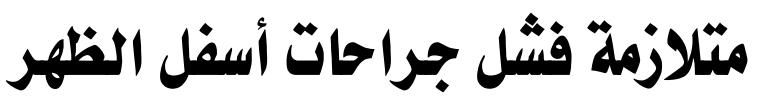 \\ محمد رمضان الصاوي، علي خضير، إسلام محمد الأجهوري}

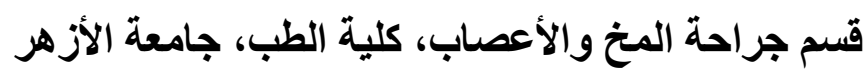

E-mail: elsawymohamed666@gmail.com

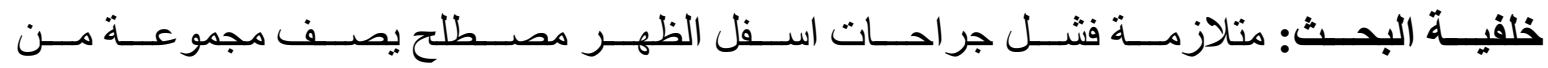

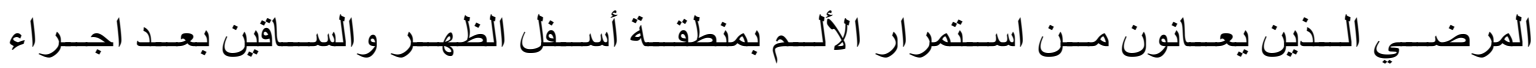
جر احات بالعمود الفقري لعلاج الألم.

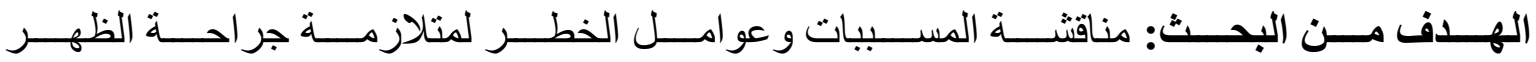

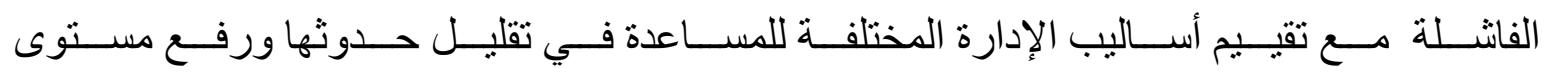
نتائج المريض.

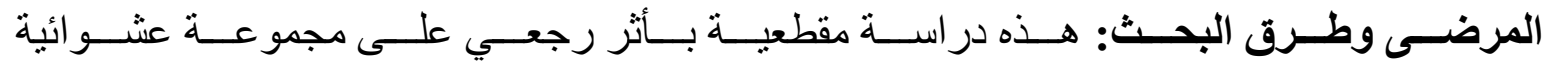

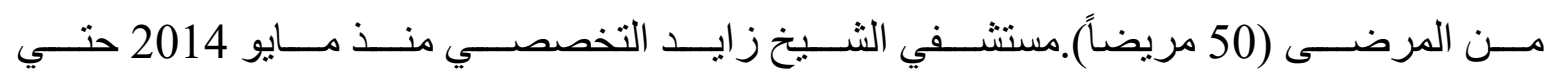

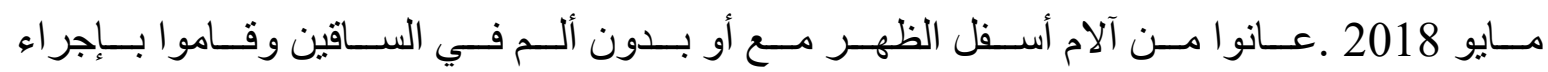

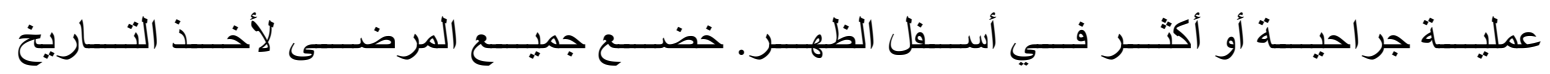

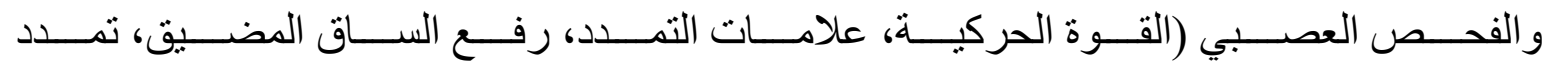

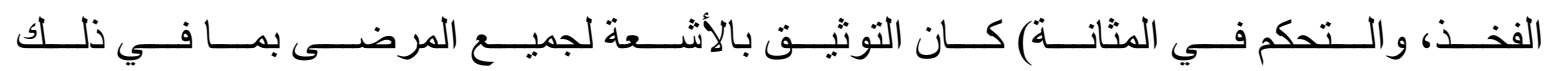
التصوير بالرنين المغناطيسي وتضيق العمود الفقري القطني.

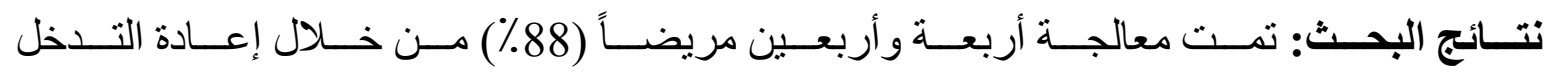

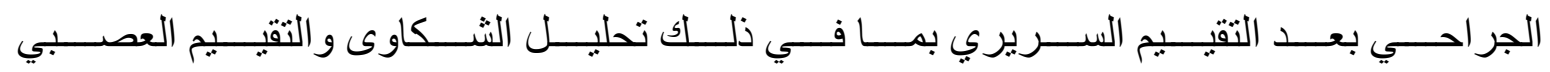

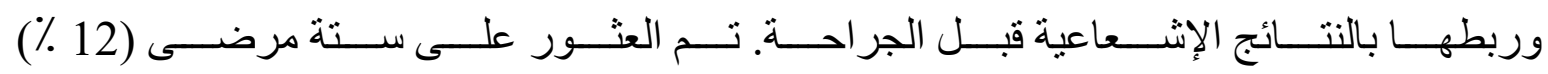
ليس لليهم نتائج إنعاعية مرتبطة بشكاو اهم.

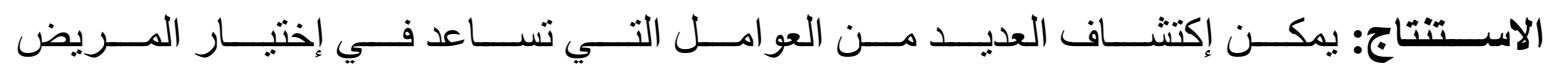

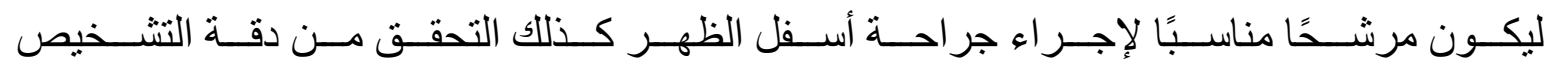

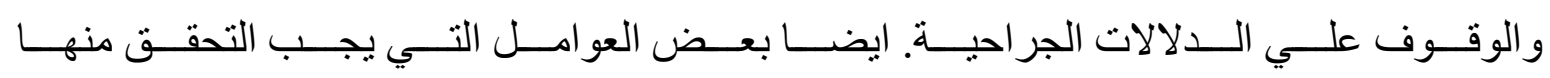
اثناء الجر احة و التي قد تؤدي لفثل الجر احة. الكلمات الدالة: متلازمة فنل جر احات اسفل الظهر. 